\title{
Kafka e Begley: entre as guerras da identidade no século XX
}

\section{Kafka and Begley: between identity wars in the 20th century}

Jeferson Ferro*

Resumo: Este trabalho analisa a trajetória dos protagonistas em dois romances, $O$ homem que se atrasava (BELGEY, 1994), e O processo (KAFKA, 2006), sob a perspectiva dos conflitos de identidade que os levam à morte. Situados em dois momentos distintos do século XX, o pré-guerra $\mathrm{e}$ o pós-guerra, estes dois romances nos oferecem a oportunidade de uma análise profunda da empreitada do homem ocidental em busca da felicidade, num mundo em que a tensão entre a liberdade e o desejo de pertencimento é um fator determinante. O judaísmo recôndito de ambos os protagonistas - e, por extensão, de seus autores - é também um traço marcante que une estes dois romances. Nossa análise explora principalmente as ideias do sociólogo polonês Zygmunt Bauman, que entende a busca por relacionamentos significativos como única saída para a tarefa da construção da identidade num mundo de fronteiras pouco definidas.

Palavras-chave: Kafka. Begley. Bauman. Identidade. Judaísmo. Guerra.

Abstract: This work analyses the journey of the heroes in two novels, The man who was late (BEGLEY, 1994), and The process (KAFKA, 2006), under the perspective of the identity conflicts which lead them to death. Set in two distinct historical moments of the 20th century, the pre-war and the post-war, these two novels offer us an opportunity for a deep analysis of western man's quest for happiness, in a world where the tension between freedom and the need for belonging is a crucial aspect of existence. The hidden Judaism of both heroes - as well as of their writers - is also a significant aspect that brings both novels together. Our analysis concentrates on the ideas of Zygmunt Bauman, a Polish sociologist who understands that the search for meaningful relationships is the only possible way to fulfill the task of self-identity in a world of blurred borders.

Keywords: Kafka. Begley. Bauman. Identity. Judaism. War.

\section{A verdade nos interessa?}

Estabelecer a verdade dos fatos é o objetivo primordial de um processo jurídico, pois sem isto não se pode julgar as ações dos indivíduos no âmbito da lei. A comprovação científica de uma tese, por sua vez, envolve a reprodução de um dado experimento de forma a confirmar seus resultados,

\footnotetext{
* Mestre em Literatura - Universidade Federal do Paraná; professor do Centro Universitário Internacional Uninter. E-mail: <jefferro@uol.com.br>
} 
que devem se manter inalterados nas diversas vezes em que o experimento for realizado, desde que preservadas as mesmas condições ambientais. E a verdade literária, o que é?

A ficcionalidade se tornou condição comum para todos os tipos de discurso em nosso contexto pós-moderno, uma vez que vivemos em uma era que abdicou do conceito singular de verdade. Edward Forster, fazendo uma crítica ao realismo literário então vigente no início do século passado, alertava para o perigo de se aproximar demasiadamente do "real": "Quando tentamos traduzir a verdade de uma esfera para outra, seja da vida para os livros, seja dos livros para a vida, algo acontece com a verdade: ela dá errado". (FORSTER, 2005, p.38).

Já Margaret Atwood, em texto recente sobre o vencedor do prêmio Nobel de Literatura no ano de 2006, Orhan Pamuk, parece estar fazendo o caminho inverso: "Pamuk nos dá aquilo que todos os romancistas nos dão em seus melhores momentos: a verdade. Não a verdade das estatísticas, mas a verdade da experiência humana em um determinado lugar e um determinado tempo". (ATWOOD, 2006). Este distanciamento de pontos de vista sobre a relação "mundo real \& ficção", num espaço tão curto de tempo, é revelador da trajetória do pensamento ocidental ao longo do século XX e, sobretudo, da maneira como avaliamos a literatura, o que nos interessa mais especificamente.

Há algum tempo passamos - não apenas nós, os estudiosos da literatura, mas também o cidadão comum, "o mero leitor" - a acreditar que toda declaração é, ao menos em certa medida, ficcional, independente da definição que possamos dar a este termo. Nem a religião ou a ciência podem mais definir as coisas de forma objetiva, ou seja, tornaram-se incapazes de nos oferecer respostas confiáveis às grandes questões humanas ${ }^{1}$. Compreendemos que 0 próprio sistema de significação das línguas humanas, o sentido das palavras e, consequentemente, de tudo a que elas se referem - na prática, tudo o que existe, e inclusive o que não existe - é volátil. Onde um dia houve certezas, hoje há apenas discurso. É no campo da linguagem, portanto, que os debates que realmente importam passam a ser travados.

Não causa surpresa que muitos cientistas "sérios" - entenda-se, os praticantes das chamadas ciências exatas - sintam-se bastante incomodados com esta radical desconstrução da secular autoridade científica. O filósofo

HALL, 2004. 
Bruno Latour descreveu bem, há algum tempo, este sentimento em artigo sobre a atual "guerra das ciências" nas universidades norte-americanas:

Aos olhos de um reduzido número de cientistas de maior ou menor prestígio [...] a universidade foi tomada de assalto por um bando de obscurantistas chamados "pós-modernos", que há 20 anos solapam as bases da civilização ao negar que se possa atingir verdades universais, depuradas dos vestígios da fabricação humana. (LATOUR, 1998).

Se " $2+2=4$ ” já não é uma afirmação confiável, o que dizer então da literatura? $\mathrm{O}$ que a literatura pode nos dizer sobre o mundo e de que vale isso tudo?

A relativização do conhecimento e das bases científicas com as quais lidamos, que ganhou força em virtude dos estudos da linguagem realizados na segunda metade do século passado, parece estar longe de ter alcançado seu ponto de equilíbrio, haja vista as reações viscerais que têm provocado. Para os estudos literários, é certamente interessante estar no centro de uma discussão que põe em jogo o próprio conceito de ciência. Também nos é favorável o fato de que filósofos da ciência e sociólogos, como Richard Rorty e Zygmunt Bauman, entre outros pensadores contemporâneos, tenham buscado na literatura um ponto de apoio para o desenvolvimento de suas teorias, lançando novos olhares sobre o fazer literário e trilhando um caminho em sentido inverso ao que estávamos tão acostumados.

Todavia, ainda que concordemos em atirar tudo o que é produzido pelas diversas culturas humanas no grande balaio chamado "linguagem", não podemos tratar ciência, religião e arte de formas idênticas. Entender que estas formas de conhecimento, se assim podemos chamá-las, são em sua essência produtos de linguagem não significa dizer que sejam equivalentes. Tampouco é necessário privar os estudos literários do poder de referencialidade da linguagem para assim isolar a obra literária como objeto de estudo científico, protegendo-a da contaminação com uma possível, ainda que indefinível, realidade - já vimos que tentativas neste sentido foram pouco proveitosas.

Ainda que a literatura não possa ser vista como um reservatório da "verdade", seja porque ela não se propõe a isto ou porque a verdade simplesmente não existe, podemos entender uma obra literária como construtora de verdades particulares, circunstanciais, que se relacionam com o mundo por 
meio do universo discursivo em que ela se inscreve. A arte fala do mundo, mas não se quer dogmática como a religião ou definitiva como a ciência. Luiz Costa Lima, em suas investigações sobre a mímesis, termo fundador dos estudos literários, e que trata especificamente da relação arte e mundo, lança luz sobre a questão: "Se a vocação do conceito é a uniformização do particular, a mímesis atua em sentido contrário. Por ela, o particular se pluraliza por dentro. A mímesis procura o subsolo. O prazer que ela é passível de provocar não cancela o espanto”. (LIMA, 2006, p.207). A investigação literária não terá como fim a universalização de conceitos ou o aprisionamento de verdades não-transitórias, ainda que esta tentativa lhe seja válida em algum momento, mas buscará oferecer uma visão privilegiada sobre as relações humanas, situadas discursivamente por um dado conjunto de obras. Esta visão, capaz de revelar o mecanismo do espanto de que nos fala Lima, é precisamente o que buscamos enquanto estudiosos da literatura.

Os autores aqui abordados, Franz Kafka e Louis Begley, são representantes de épocas, línguas e estilos literários distintos. Entretanto, acreditamos ser possível aproximá-los sob um ponto de vista: o da construção da identidade do homem ao longo do século XX. Pretendemos investigar como cada autor, em seu contexto, constrói um universo discursivo que dialoga com o mundo e ocupa seu espaço ao longo de uma linha de pensamento que vai do pré-guerra aos dias de hoje. Teremos sido bem-sucedidos se lograrmos lançar alguma luz sobre o tema e estabelecer um ponto de encontro entre as obras destes autores.

\section{Josef K. e Ben: dois heróis para nosso século}

Neste texto, identificamos dois momentos histórico-discursivos distintos, caracterizados ficcionalmente pelos autores estudados, que aproximamos sob o aspecto da construção da identidade do homem moderno. O primeiro deles nos é trazido pelo romance $O$ processo, de Franz Kafka, no qual identificamos uma antevisão do estado de desenraizamento e insegurança que se agravaria para o homem do pós-guerra, estado este que consideramos fundamental para a investigação das questões da identidade na contemporaneidade. As agruras vividas pelo herói do romance, Josef K., que culminam com sua execução, são reveladoras do conflito entre o desejo de liberdade do homem moderno e a força do Estado empenhado na construção de uma ordem superior, representado no romance pelo poder jurídico. Em O processo, Kafka 
provoca no leitor os angustiantes sentimentos do absurdo e da impotência, vividos na carne pelo protagonista, diante de uma força inabalável, a lei. Esta força, por sua vez, nos remete aos projetos de estado totalitaristas que, pouco tempo depois da escritura deste romance, conheceriam seus limites com a empreitada nazista.

Em seu comentário a um dos textos mais importantes de Freud, $O$ mal- estar na civilização, Zygmunt Bauman analisa a sociedade contemporânea sob a ótica do grande valor conquistado pelo homem do século XX: a liberdade de escolha. Segundo Bauman, "este é o valor pelo qual todos os outros valores vieram a ser avaliados e a referência pela qual a sabedoria acerca de todas as normas e resoluções supra individuais devem ser medidas." (BAUMAN, 1998b, p.9). A síntese do pensamento de Freud aponta para as antíteses "dor x prazer", "liberdade x segurança". Como alerta Bauman, comentando o psicanalista: "Dentro da estrutura de uma civilização que escolheu limitar a liberdade em nome da segurança, mais ordem significa mais mal-estar." (idem) Ou seja, o progresso da sociedade ocidental, que se manifesta de forma bastante concreta na construção de instituições que têm como objetivo promover o bem comum (o Estado e todo o seu aparato jurídico, policial etc.), guarda em seu âmago um paradoxo: o conflito entre o desejo de liberdade do indivíduo e a sua necessidade de segurança, que se realiza na coletividade. Este conflito se tornou bastante evidente nos projetos totalitaristas europeus do início do século XX. O Nazismo foi o mais radical deles, procurando impor uma ordem de pureza racial e ideológica a toda a humanidade, o que, inevitavelmente, significava exterminar todos aqueles que não se encaixassem na tal ordem.

O Holocausto foi um divisor de águas no século XX, e também o será para nossa análise literária. Por isso é importante ressaltarmos que, diferente do que se pode tomar como a ideia mais corriqueira, não entenderemos aqui o Holocausto como um fato isolado da história ocidental, uma ferida que a civilização moderna logrou curar. Devemos ter claro que o Holocausto foi antes um "legítimo produto de nossa civilização", como disse Bauman, o resultado de uma peculiar manifestação de pulsões humanas que, não obstante a lição histórica, continuam a existir. Nas palavras do sociólogo polonês: "O Holocausto nasceu e foi executado na nossa sociedade moderna e racional, em nosso alto estágio de civilização e no auge do desenvolvimento cultural humano, e por essa razão é um problema dessa sociedade, dessa civilização e cultura”. (BAUMAN, 1999, p.14). Por isto mesmo, manter este acontecimento histórico, bem como suas consequências, 
em nosso horizonte investigativo, parece-nos essencial para a compreensão dos problemas de identidade do homem moderno.

O conflito entre a recôndita condição judaica de Kafka e sua posição social como cidadão do Império Austro-Húngaro permaneceu latente em toda sua obra, ganhando representações alegóricas em seus textos. Esse conflito, por sua vez, é bastante representativo do que mais tarde viria a caracterizar a condição moderna do homem no pós-guerra: "Ele próprio um estranho universal e talvez o mais perspicaz dos estranhos universais, Kafka desfiava e delineava os traços universais da estranheza nesse único e verdadeiro herói, embora com muitas faces, de toda sua obra literária”. (BAUMAN, 1999, p.101). Esta noção de estranheza, bem como seu oposto, a ideia de pertencimento, são fundamentais para nossa investigação. Segundo Bauman, os estranhos são as pessoas que "não se encaixam no mapa cognitivo, moral ou estético do mundo", sua presença confunde as fronteiras da "ordem", gerando a incerteza e poluindo a alegria com a angústia. (BAUMAN, 1998b). Neste sentido, o estranho é a encarnação da "sujeira", o elemento definidor da desordem. É bastante evidente como esta interpretação se encaixa no projeto nazista e no seu programa de estabelecimento de uma ordem "pura". Em O Processo, encontramos um diálogo que aponta para o sentimento de exclusão do protagonista, quando este conversa com sua senhoria a respeito da Srta. Bürstner, sua vizinha de quarto na pensão:

Afinal, é do interesse de todo inquilino que se procure conservar limpa a pensão, e não foi outro o meu empenho.

- Limpeza! - ainda exclamou K. pela fresta da porta. - Se quer conservar limpa a pensão, precisa primeiro me despejar. (KAFKA, 2006, p.34).

Esta declaração de K. é um forte indicativo de que sua aparente estabilidade - afinal ele era um homem bastante respeitável e ocupava um alto cargo num banco importante de sua cidade - escondia um "desencaixe" latente. É como se o protagonista anunciasse, já no início do romance, que algo estava errado com ele, havia algo de "sujo" em sua existência naquele mundo, e assim nos preparasse para o processo de limpeza que viria a seguir. Este "confronto com a sujeira” será também um aspecto marcante no romance de Begley.

Uma vez que a obra de Kafka é bastante conhecida, vamos fazer agora uma breve apresentação do romance de Louis Begley, O homem que se atrasava, que nos remete ao segundo momento em nossa análise desta travessia, 
momento este que acontece justamente no pós-guerra. Ben, o protagonista do romance, é o mais pontual e impecável dos homens no trato profissional. Porém, na vida sentimental ele está sempre perdendo o trem. Sua história é narrada por Jack, jornalista e escritor, seu único amigo e confidente, hoje de posse de seus diários pessoais. Não sabemos desde o início da história que Ben morre no final, mas temos algumas pistas de que isto irá acontecer - caso contrário, por que Jack teria seus diários? A partir de seu conhecimento próprio dos fatos, de entrevistas com pessoas que viveram próximas a Ben e de notas de seus diários, que serão transcritas ao longo da narrativa, Jack reconstrói a trajetória do amigo, desde seus dias de estudante universitário nos EUA até o suicídio em Paris.

O narrador começa com um breve relato da promoção de Ben à high society norte-americana nos anos sessenta, como um autêntico self-made man. Ben era um judeu refugiado de guerra, de família modesta. Serviço militar na Europa e faculdade de direito em Harvard haviam the dado as credenciais necessárias para se aproximar da alta burguesia norte-americana. A narrativa se concentra, então, na época da maturidade de Ben, após o divórcio com Rachel, a mulher que o introduzira definitivamente naquele mundo. Trata-se do período de sua ascensão profissional, que o leva a se tornar sócio de uma grande firma de advocacia com escritórios nos EUA e na Europa e negócios na Ásia e no Brasil, sucesso este que irá se opor radicalmente a seu fracasso em estabelecer relações duradouras de amor e amizade.

Após seu irrevogável estabelecimento no mundo do dinheiro, para o qual o casamento com uma viúva rica servira de porta de entrada, segue-se o aprofundamento do paradoxo "sucesso profissional X fracasso emocional" na vida de Ben, que gradualmente emergirá na forma de uma crise de identidade esmagadora. À medida que se familiariza com o mundo da alta sociedade, ele se afasta de seu passado de refugiado pobre e, consequentemente, de seus pais judeus, que não tardam a falecer. Seu casamento com Rachel também não durara muito e, pior, sua relação paterna com as duas enteadas, construída tão cuidadosamente por ele, termina tragicamente com uma acusação de assédio sexual feita por sua ex-esposa.

Desta forma, ao atingir a maturidade Ben é um homem só, sem vínculos significativos além daqueles postos por seu trabalho, um herói do mundo desestruturado, destruído pela guerra: sem pátria, sem ideologia, sem religião, sem família. A solidão e o desgosto por uma vida de relacionamentos 
frustrados começam a dar sinais de forte enraizamento em seu coração. Vivendo em Paris, ele mergulha num ciclo de conquistas profissionais e prazeres mundanos - muito sexo casual, bebida e culinária requintada. Ben não tem pudor algum em colher os frutos materiais que seu sucesso proporciona, e faz questão de viver com extrema elegância. Seu cuidado exagerado com as roupas que encomenda, com os lugares que frequenta e a casa em que vive - acrescentados à sua indiferença um tanto niilista por preocupações cotidianas, como a política - adquire um aspecto de higiene estética que de certa forma o isola do lado ruim da vida. Esta "higiene", por outro lado, revela uma recusa deliberada em aceitar qualquer comprometimento num mundo que se apresenta instável, exceto no campo do trabalho, onde Ben opera com total segurança.

O estilo de vida que alternava grandes doses de trabalho com outras de prazer, todavia, não resistiria por muito tempo. É pela via do trabalho, que Ben sempre se esforçara por manter assepticamente distante das questões pessoais, que chega a mudança: ele conhece Veronique, a encantadora esposa de um advogado francês que presta serviços para sua firma, e os dois se apaixonam perdidamente. Veronique é também prima de Jack, o narrador, e tem um filho pequeno com seu esposo. Apesar de Ben fazer certo esforço para manter as coisas "limpas", logo o caso se torna público e o marido traído reage com violência. Inicia-se então um perverso jogo de dominação no triângulo amoroso que liga Ben, Veronique e seu esposo, envolvendo sexo, violência física e dinheiro.

O divórcio não acontece e Ben e Veronique continuam se encontrando, já nem tão secretamente. Quando as condições finalmente se apresentam para que os dois fiquem juntos, Ben hesita. O medo de outro fracasso emocional, de não ser capaz de corresponder ao amor de Veronique, de não ser bem sucedido como pai de um filho que não é seu, o paralisa. Seu receio em assumir o amor - e, neste caso, o risco que ele envolve - por Veronique, um receio que ela não tem, pois the faz uma declaração apaixonada durante um jantar com a família do esposo, o leva a mergulhar no trabalho. Como estamos no início dos anos setenta, sem Internet ou telefones celulares, portanto, um compromisso profissional de Ben no Brasil, que se estende além do previsto com viagens ao Japão, torna-se o responsável - o álibi emocional perfeito, diríamos - por uma série de desencontros que deixam Veronique isolada, justo no momento mais crítico do relacionamento com seu marido, quando ela pede o divórcio. Uma troca confusa de cartas deixadas em hotéis, sempre lidas com atraso, intensifica 
a angústia do momento. Ben acaba submergindo numa orgia tropical - afinal, ele está no Rio de Janeiro! - de sexo e trabalho, enquanto Veronique queima na fogueira que ela própria acendera.

Uma vez que Ben não fora em seu socorro quando ela mais precisou - na verdade, ele simplesmente desapareceu - Veronique não resiste à pressão do marido e sucumbe. Ela acaba sendo dominada. Quando, muito tardiamente, Ben volta a se encontrar com ela, o relacionamento dos dois já não é mais possível. Só resta o gosto amargo da chance perdida, que se concretiza de forma bizarra: Veronique, num ato de suicídio emocional, engravida de um estranho com quem tivera uma relação casual durante uma viagem aérea. Se Ben tinha tanto receio do relacionamento que poderia não dar certo, agora terá que viver com a enorme culpa de ter arruinado a vida da mulher por quem se apaixonara.

O que se segue é o processo rápido de depressão de Ben, com alguns lances de desespero, que culmina em seu suicídio. Tal como o herói trágico shakespeariano, Ben vislumbra a iluminação, se podemos dizer, quando se aproxima do fim: ciente de sua condição de homem "desenraizado", pois não tem pátria ou família, casa ou amigos, ele se compara a seu dentista, também um refugiado europeu que alcançou sucesso na América:

Tivesse eu porém me mantido fiel à minha própria espécie, eu mesmo talvez pudesse ser assim. Não gosto da minha própria espécie, esse é um problema; não sei qual é minha espécie, esse é outro. (BEGLEY, 1994, p.171-2).

Podemos ler nesta declaração do protagonista uma manifestação clara do conflito existencial que chega ao seu limite. Filho da guerra, vivendo num mundo ao qual não pertence, buscando na glória profissional e na riqueza a felicidade, Ben abraçou a compulsão pelo sucesso material como a forma mais clara de provar seu valor numa sociedade capitalista. Ao sufocar seus problemas emocionais e questionamentos existenciais, como este que transcrevemos acima, ao longo de sua escalada Ben se esquivou, enquanto pôde, de um confronto inevitável consigo mesmo. $\mathrm{O}$ momento cruel da solidão profunda, todavia, o espreitava desde sempre.

A condição judaica é um importante fator de aproximação entre os heróis aqui estudados, bem como de seus autores. Sob o ponto de vista da questão da identidade, o judeu se configura como um ser emblemático para o século XX. Na Europa do pré-guerra, os judeus eram a própria encarnação 
da estranheza, um povo sem lar ou raízes definidas, um nacionalismo sem nação, uma população errante. Eram estranhos universais, portanto. Não por outro motivo se tornaram o alvo principal de um movimento que procurava estabelecer uma ordem superior a todo o planeta. Os judeus encarnavam a própria condição da desordem, e por isto estariam fadados à eliminação completa.

Se Kafka, judeu integrado à cultura germânica da Praga no período do pré-guerra, criou um herói angustiado que leva às últimas consequências um conflito individual com o Estado, Begley, judeu sobrevivente do Holocausto, homem de sucesso no mundo capitalista norte-americano, escreveria ao final do século XX um romance cujo herói sucumbe diante da armadilha imposta por esta que é a grande conquista da humanidade no século XX: a liberdade de escolha. Ben tarda a descobrir que a liberdade de construirmos nossas identidades, de sermos o que queremos ser - este autêntico slogan comercial que parece resumir a condição do homem contemporâneo - não é tão real quanto parece, e seu encontro final com o absurdo de uma identidade vazia termina por levá-lo ao suicídio.

A obra de Kafka pode ser vista como uma parábola do transe universal do homem moderno: K. é o herói sem nome, carregando uma culpa sem crime, que termina condenado sem julgamento. O processo nos apresenta de forma claustrofóbica o sufocamento das liberdades individuais, a irônica falência de um ideal de racionalidade e justiça, antes mesmo que o mundo conhecesse a sua forma mais expressiva: o projeto nazista. Assim, podemos entender a obra deste autor como uma crítica sarcástica ao modelo de estado totalitário, racional e científico que se colocava como ideal no início do século XX:

Num mundo dominado pelo medo mortal de tudo o que é contingente, opaco e inexplicável, a ficção artística é uma contínua sessão de treinamento para viver com o ambivalente e o misterioso. Ela ensaia a tolerância e equanimidade para $o$ inconstante, o contingente, o não inteiramente determinado, o não inteiramente compreendido e o não inteiramente previsível. Incentiva a reconciliação com a contingência da vida e a polifonia de verdades. (BAUMAN, 1998b, p.148).

Já em Begley, no pós-guerra, o mundo da liberdade e do sucesso material atira o homem num beco sem-saída existencial: falta-lhe o substrato que dá sentido à vida, falta o pertencimento. Nem mesmo o homem que "fez tudo certo", que alcançou o sucesso seguindo as regras e venceu no jogo dos grandes homens, pode escapar ao absurdo de uma existência sem raízes. 
Ao mesmo tempo em que é reveladora dos limites que a ordem social da liberdade de escolha hesita em revelar, a obra de Begley se encontra num outro momento da ficção no século XX, num momento em que nós, leitores, "procuramos a espécie de certeza e segurança intelectual que o mundo real não pode oferecer... Lemos romances a fim de localizar uma forma na informe quantidade de experiências terrenas". (BAUMAN, 1998b, p.151). Se o mundo contemporâneo parece insistir em nos dizer que nada mais faz sentido por muito tempo, encontramos na obra de Begley uma clara lição de que há limites e consequências para o jogo de criação da identidade, pois há certas "verdades" de que não se pode fugir a vida toda.

Em tese, os protagonistas Ben e $\mathrm{K}$. foram eliminados por algozes distintos. Enquanto o herói do pré-guerra foi executado pelo Estado, na calada da noite, "feito um cão", o herói do pós-guerra se atirou de uma ponte após ter tomado uma overdose de calmantes, em meio a uma crise depressiva. Mas até que ponto os algozes de nossos heróis são realmente opostos? Para responder a esta pergunta, vamos procurar as raízes da culpa que os levou ao cadafalso.

\section{Morte aos que não sabem quem são}

Para Kafka, a vida em Praga no começo do século guardava um conflito de identidade imanente: judeu em casa, cidadão "germanizado" na rua. Um conflito similar pode também ser lido na trajetória do herói de O processo. K. era certamente um homem bem-sucedido nos trâmites profissionais, e a importância dada a este fato torna-se evidente já no momento de sua primeira detenção: ele fica bastante desconcertado com a presença, ao evento, de funcionários do banco onde trabalhava; mais tarde, menciona com a Sra. Grubach que não teria sido pego "desprevenido" por aqueles oficiais de justiça caso estivesse em seu escritório. Em outro momento ainda, numa conversa em que procurava esclarecer os acontecimentos com sua senhoria, oferece-lhe a mão, convidando-a a um cumprimento, gesto típico do mundo dos negócios, que não se realiza e acaba criando uma situação bastante constrangedora. Desde o início do romance, portanto, percebemos que existe uma oposição clara entre dois mundos: de um lado, o asseio da vida profissional de K., onde impera a ordem; de outro, o âmbito do processo no qual ele se vê envolvido, onde reina o descontrole e a imprevisibilidade. Esta dualidade se apresenta de forma semelhante ao que encontramos no romance de Begley, no qual o protagonista também se coloca numa situação de oposição clara entre o 
universo do trabalho - asséptico, racional, ordenado, seguro - e o das relações pessoais, que se revelam caóticas e o levam à morte.

Se em Begley a "anti-ordem” está claramente estabelecida no âmbito das relações pessoais, em Kafka ela se encontra como que disfarçada na forma do processo movido contra K. É no desenrolar das complicações oriundas com o processo que o herói mostra sua fragilidade e a sua decadência se configura. Não por acaso, esta fragilidade estará sempre associada à libido, pois em praticamente todas as instâncias do processo pelas quais K. passa haverá envolvimento com alguma mulher. Estes envolvimentos, por sua vez, estarão sempre contaminados por uma aura de proibição. No dia de sua detenção, o Sr. K. força um encontro com a Sra. Bürstner, sua vizinha de quarto na pensão, encontro este que termina tal qual um coito interrompido quando, após pressioná-la com beijos que a dama parece recusar, K. é finalmente afastado pelo perigo iminente de terem chamado a atenção do capitão, hóspede instalado na sala ao lado. Já na primeira audiência de seu processo haverá o encontro com a mulher do oficial de justiça, que é assediada pelo estudante de direito. Esta mulher imediatamente se torna objeto de desejo de K., por quem ele ousará enfrentar o influente estudante de direito. Há ainda o envolvimento com a governanta de seu advogado, já a caminho do final do processo, causando um profundo mal-estar entre o réu e seu defensor. Em todos estes casos, a sensação de que K. está fazendo algo de errado é sempre nítida.

A pretensa casualidade destes encontros revela, na verdade, uma espécie de "compulsão ao pecado", se assim podemos dizer. Poderíamos entendê-la pela ótica freudiana do desejo reprimido, e como tal traçar um paralelo que a aproximasse da condição judaica reprimida do próprio autor. Mas preferimos ir um pouco além e entender o comportamento impulsivo de K. não como uma simples manifestação de desejos reprimidos, mas antes uma "declaração estética" de que a proposta de ordem e racionalidade, ironicamente representada no romance pelo Estado de Direito, está fadada ao insucesso. Na leitura feita por Eagleton sobre a proposta estética de Freud: "Nossos corpos não são gloriosamente autônomos, como Nietzsche tende a imaginá-los, mas presos por sua evolução aos corpos de outros, e por isso acontecem essa hesitação e desvio traiçoeiros de nossos impulsos". (EAGLETON, 1993, p.192). A “ordem" como o grande projeto de felicidade coletiva no século XX agravaria, ao restringir as liberdades individuais e mirar na segurança, o mal-estar cujas origens se encontram em nossa eterna insatisfação. 
Em Begley, não há empecilhos à realização dos desejos sexuais do protagonista, pois Ben é um homem livre, rico e habita o mundo da alta-burguesia norte-americana e europeia dos anos sessenta e setenta, condições que o deixam numa posição bastante privilegiada para o exercício de suas aventuras amorosas. Porém, a sua fixação com a "ordem" ultrapassa os limites do mundo do trabalho e abarca outras instâncias de sua vida na forma de uma "compulsão à elegância", uma espécie de purismo estético que o leva a estar sempre preocupado com suas roupas, seus gestos e atitudes, fazendo-o avaliar cada passo que dava em função da imagem que criaria, como nesta passagem em que ele hesita entrar na fila de uma padaria em Paris: "Seria por não querer que a mulher afável de gestos rápidos [...] o classificasse no mesmo nível que os outros homens, tão amargos e cautelosos, também à espera para fazer as compras para um jantar solitário?" (BEGLEY, 1994, p.69). O extremo cuidado com a elegância e a ordem não impediria, no entanto, que "o mais pontual e confiável dos homens se atrasasse nas matérias mais importantes da existência" (BEGLEY, 1994, p.7), caracterizando assim a sua "falha trágica".

Sabemos que o equívoco de Ben se manifestará no âmbito das relações pessoais. No romance de Kafka, por sua vez, o universo dos relacionamentos humanos não chega a ser tão bem caracterizado, e as investidas sexuais do protagonista nos parecem bastante representativas de um impulso de liberdade mais primitivo. Entretanto, acreditamos ser possível aproximar Ben e K. sob o ponto de vista do poder de decisão do indivíduo. Neste sentido, a deliberada incapacidade de K. em se defender ao longo do processo, sobretudo graças aos seus equívocos quase que propositais na condução de sua defesa, caracterizaria sua execução final como um ato de autopunição, quase um suicídio propriamente, o que o igualaria a Ben, ainda que por motivações distintas. Logo no início do romance, lemos uma passagem que aponta para esta possibilidade:

Surpreendia K. - pelo menos do ponto de vista dos guardas isso o surpreendia - que o tivessem metido no quarto e o deixado ali sozinho, onde sem dúvida tinha dezenas de possibilidades de se matar. Ao mesmo tempo, porém, se perguntou - dessa vez do seu próprio ponto de vista - que motivo poderia ter para fazer isso? (KAFKA, 2006, p.17).

K. não responderia a esta pergunta, mas embarcaria numa viagem de libertação, contrariando a voz do bom-senso, que culminaria com sua execução final. O momento desencadeador de todo este processo, acreditamos, encontra-se ao final do segundo capítulo, que descreve o primeiro inquérito. $\mathrm{K}$. havia recebido um telefonema informando-o da data e local onde deveria 
comparecer. Ao desligar o telefone, depara-se com o diretor do banco, que o convida para uma festa em seu veleiro no domingo, o mesmo dia do inquérito, portanto. K. reflete por alguns segundos sobre a importância de comparecer àquela festa, que contaria com a presença das pessoas mais destacadas de seu banco, e na humilhação que uma negativa significaria para o diretor que o convidava. No entanto, não hesita, respondendo que infelizmente estaria ocupado e não poderia ir. A seguir, embarcamos no absurdo mundo do processo, acompanhando a caótica busca do protagonista pelo lugar onde se realizaria o tal inquérito. Quando K. finalmente chega ao lugar, percebe que o juiz de instrução sequer sabe quem ele é ou tem qualquer informação a seu respeito. Não obstante, K. se põe a discursar agressivamente contra aquele tribunal, anunciando sua inocência e indignação diante de uma acusação infundada. Ao final, a declaração do juiz de instrução revela o enigma: "Só queria chamar a sua atenção - disse o juiz - para o fato de que o senhor hoje - isso ainda não deve ter chegado à sua consciência - se privou da vantagem que um inquérito, de qualquer modo, representa para o detido". (KAFKA, 2006, p.64). O tribunal, sabemos disto desde o momento da primeira detenção, é atraído pela culpa - "Nossas autoridades, até onde as conheço, e só conheço seus níveis mais baixos, não buscam a culpa na população, mas, conforme consta na lei, são atraídas pela culpa". (KAFKA, 2006, p.15). Ao fazer sua escolha, comparecer ao inquérito ao invés de ir à festa no veleiro do diretor do banco, e ao se pronunciar tão veementemente em defesa de sua inocência num tribunal que sequer o havia acusado nominalmente, K. havia, na verdade, assumido a condição de réu, da qual só a morte o libertará.

Se entendemos a trajetória de K. como uma opção - inconsciente, talvez - pela via da libertação, em oposição a uma ordem castradora à qual ele sentia não pertencer, então o capítulo nono, $\mathrm{Na}$ Catedral, será bastante revelador. É nele que K. encontrará um interlocutor para seus questionamentos, o sacerdote, e ouvirá dele a fábula "Diante da Lei". O que nos interessa aqui, todavia, é o trecho em que, diante da cena do sacerdote que se preparava para iniciar um culto para uma igreja vazia, pois K. era o único "fiel", lemos o seguinte: "Mas era realmente possível haver um sermão? Será que K. poderia sozinho representar a comunidade? E se ele fosse um estrangeiro que quisesse apenas visitar a igreja? No fundo, não era outra coisa". (KAFKA, 2006, p.255). Poucas vezes no romance teremos respostas tão claras como esta.

No romance de Begley, é à condição de judeu que o herói se volta quando nada mais parece fazer sentido em sua vida. Ben tinha consciência deste sentimento de não-pertencimento desde o início: "Sou como Tarzã, um 
estranho homem-macaco que perde uma infância mas não sei como pular de uma árvore para outra nem ser amado por Jane". (BEGLEY, 1994, p.76). E quando se sente pressionado pelos acontecimentos, parece não ter outro refúgio que não seja a sua condição primeira como ser humano neste mundo, que é o judaísmo, como demonstra em sua reação às ameças do marido traído: "Quando conhecer melhor os judeus, perceberá a extraordinária insensibilidade de que são capazes". (BEGLEY, 1994, p.99). O momento definidor de sua condição de expatriado, o horror da guerra, que condicionou em grande medida o que viria a acontecer com o homem ocidental no século XX, cresce em importância à medida que o romance caminha para seu desfecho. Assim, se a Segunda Guerra Mundial é o trauma fundador da condição de desenraizamento de Ben, será também seu ponto de referência quando ele precisar saber quem é e do que é capaz. Mais tarde, ao fracassar em sua tentativa de unir-se a Veronique, Ben irá se comparar ao dentista judeu de Nova Iorque e perceber que sequer um "judeu” ele pode ser. No fim, tal como K. descobre na catedral, ele era simplesmente um estrangeiro.

Os conflitos de Ben e K., que culminam com suas mortes, são ambos representativos dos impasses vividos pelo homem moderno na árdua, porém inevitável, tarefa de estabelecer sua identidade, condição essencial para sua realização pessoal. O projeto moderno, ao libertar o homem da identidade herdada, fez com que a identidade passasse a ser uma questão de realização, uma tarefa de responsabilidade do indivíduo (BAUMAN, 1998b). Kafka capturou o momento em que esta liberdade de escolha era ainda confusa, e o conflito entre o indivíduo e o Estado, que se pretendia a legítima manifestação de uma identidade coletiva, anunciava consequências nada promissoras. Já Begley, no pós-guerra, se encontraria num mundo em que "o deslocamento das responsabilidades de escolha para os ombros do indivíduo, a destruição dos sinalizadores e a remoção dos marcos históricos, rematados pela crescente indiferença dos poderes superiores em relação à natureza das escolhas feitas e à sua viabilidade" (BAUMAN, 2005, p.57) se tornariam mais evidentes. Com isso, se por um lado a condição moderna caracteriza um mundo que oferece mais liberdade, por outro parece tornar-nos órfãos de tudo.

Para ambos os heróis, o universo dos relacionamentos pessoais se configura como uma saída, ainda que eles tenham sido incapazes de aproveitá-la, para o abismo do desenraizamento. Ben e K. são, sobretudo, homens em busca de vínculos amorosos, pois morrer sem deixar vestígios equivaleria a anular sua própria existência: 
[...] a essência da identidade - a resposta à pergunta 'Quem sou eu?' e, mais importante ainda, a permanente credibilidade da resposta que lhe possa ser dada, qualquer que seja - não pode ser constituída senão por referência aos vínculos que conectam o eu a outras pessoas e ao pressuposto de que tais vínculos são fidedignos e gozam de estabilidade com o passar do tempo. Precisamos de relacionamentos, e de relacionamentos que possam servir para alguma coisa, relacionamentos aos quais possamos referir-nos no intuito de definirmos a nós mesmos. (BAUMAN, 2005, p.75).

Seu fracasso, no entanto, é revelador de que nossa liberdade de escolha é tão libertadora quanto perigosa. Se para K. ela está sempre em oposição a uma ordem superior que não lhe permite realizar-se plenamente, para Ben ela é embriagante - dois lados de uma moeda que, hoje, caracteriza fidedignamente o "mal-estar da pós-modernidade" de que nos fala Bauman. Ao homem pós-moderno cabe, portanto, o desafio de buscar um ponto de equilíbrio entre a ficção que criamos sobre nós mesmos e as regras do mundo em que vivemos, ou seja, entre o que se quer ser e aquilo que não se pode deixar de ser.

\section{Referências}

ATWOOD, Margaret. Um Nobel para nossa era. Folha de S. Paulo, 22/10/06.

BAUMAN, Zygmunt. Identidade. Rio de Janeiro: Jorge Zahar Editor, 2005.

Modernidade e ambivalência. Rio de Janeiro: Jorge Zahar Editor, 1999.

Modernidade e holocausto. Rio de Janeiro: Jorge Zahar Editor, 1998.

O mal-estar da pós-modernidade. Rio de Janeiro: Jorge Zahar Editor, 1998b.

BEGLEY, Louis. O homem que se atrasava. São Paulo: Companhia das Letras, 1994.

EAGLETON, Terry. A ideologia da estética. Rio de Janeiro: Jorge Zahar Editor, 1993.

FORSTER, E. M. Aspectos do romance. São Paulo: Globo, 2005.

HALL, Stuart. A identidade cultural na pós-modernidade. Rio de Janeiro: DP\&A, 2004.

KAFKA, Franz. O processo. São Paulo: Companhia das Letras, 2006.

LATOUR, Bruno. A guerra das ciências. Folha de S. Paulo, 15/11/1998.

LIMA, Luiz Costa. História. Ficção. Literatura. São Paulo: Companhia das Letras, 2006.

Recebido para publicação em 08 de novembro de 2011.

Aceito para publicação em 14 de dezembro de 2011. 